\title{
The Myth of the Post-Communist Citizen: Communist Legacies and Political Trust - CORRIGENDUM
}

Correction to Brad Epperly (2019) "The Myth of the Post-Communist Citizen: Communist Legacies and Political Trust." Social Science History 43 (2), 297-317. doi.org/10.1017/ssh.2019.5

In the above mentioned article, plot (a) of Figure 1 is incorrect. The corrected Figure 1 appears in full below.

(a)

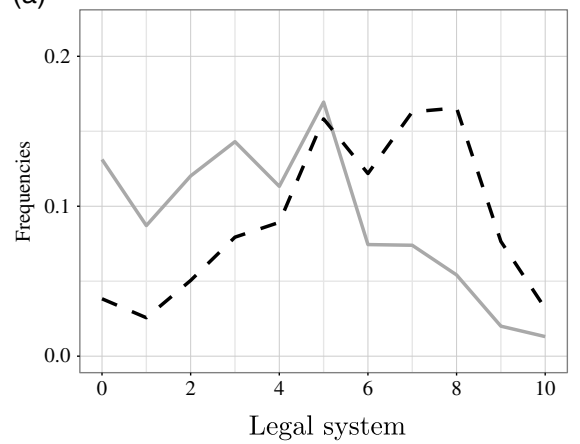

(b)

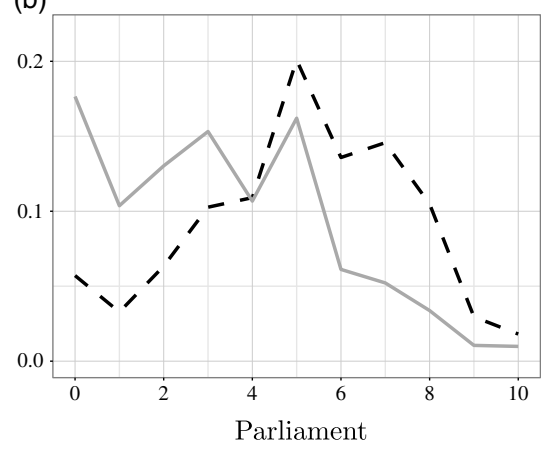

FIGURE 1. Distribution of trust. Plot (a) shows the distribution of trust in the legal system across both Western and Eastern Europe. Plot (b) shows the distribution of trust in parliament. In both, solid gray lines represent post-communist observations, dashed black shows non-post-communist. Data are from the 2002-10 waves of the European Social Survey. 